conditions requisite for iridectomy. The following is a description of the instrument:-

The limbs of these forceps do not open in the ordinary manner, but turn round a longitudinal axis in such a way that their rotation alone suffices to open and close their curved extremities. The movement of opening and shutting takes place without the part of the instrument which is engaged in the wound participating in the least degree: this part of the instrument, on the contrary, remains closed when the extremities are expanded. The size of the wound plays no part in the mode of artion of the instrument on the iris. As a result of this circumstance, the introduction of the instrument is not limited to a radial direction; it may take place in a series of other directions, all comprised in the extent of a segment of a circle of which the circumference is described by the curved extremities of the forceps taken as a radius, whilst the centre of the circle is the part of the wound in which the instrument is situated.

The application of these new forceps does not present the slightest difficulty. Holding them like a pen between the three fingers, they are opened by placing the index finger on the instrument, and closed by applying the middle finger.

The manufacture of the instrument is also sufficiently simple.

The principle on which the construction of these forceps depends has never been applied to uny surgical instrument. I believe that this principle may easily be utilised for many other instruments; but I hope, above all, that it may render important services by perfecting the operation of iridectomy.

\section{ON THE TREATMENT OF INTRA-THORACIC ANEURISM BY THE DISTAL LIGATURE.}

\section{BY CHRISTOPHER HEATH, F.R.C.S.,}

ASSISTANT-SURGEON TO UNIVERSTTY COLLEGE HOSPITAL, AND TEACHER OF OPERATIVE SERGERY IN UNIVERSITY COLIEGE, LONDON.

THE patient, Julia W-, upon whom I tied the right subclavian and common carotid arteries simultaneously in the Westminster Hospital on Nov. 21st, 1865 (vide LanceT, Dec. 2nd, 1865, and Jan. 5th, 1867), died on Dec. 8th, 1869, from the external bursting of an aortic aneurism. By the patient's own wish, I was able to have her body removed to the Royal College of Surgeons, where it was carefully injected from the abdominal aorta, and afterwards dissected by Mr. Moseley; and the preparation will be added to the College museum.

The condition of the patient at the time of the operation was as follows:-There was a pulsating tumour at the inner end of the right clavicle, which was thrust forward. The interclavicular notch, which was obscured by the tumour, could be felt on making deep pressure with the finger. The pulsation extended above the clavicle and slightly towards the sterno-mastoid muscle. When first seen there was no bruit, but subsequently a faint bruit could be heard. The patient was pale, but well nourished; she suffered considerable pain in the tumour at intervals, was unable to assume the horizontal position without distress and dyspncea, and had some difficulty in swallowing. The right radial pulse was smaller than the left.

The patient was examined by numerous physicians and surgeons of eminence, and the almost unanimous opinion was that the aneurism affected the innominate artery, though there was some difference as to whether or not the aorta was slightly involved in addition. In the week during which the patient was in the hospital under observation the tumour decidedly increased, the pressure symptoms became aggravated, and pain with numbness in the right arm came on. Under these eircumstances, and believing the aneurism to be one of the innominate artery, I tied the right subclavian artery outside the scalenus, and the right common carotid artery above the omo-hyoid muscle, on Nov. 2lst, 1865 .

In determining upon tying the two main arteries simultaneously in this case, $I$ was influenced very considerably by the arguments employed by MIr. Erichsen in his work on Surgers, wherein he shows that obliteration of one of the main trunks, whether by disease or ligature, has never been sufficient to effect the cure of the aneurism-except, indeed, in Mr. Evans's case, where, however, the cure depended probably upon inflammation extending to the sac. Supposing each of the main trunks to receive one-third of the whole volume of blood passing through the innominate, the obliteration of one of them will still leave two-thirds of the amount passing through the aneurism. But in addition to this, there should, I think, be taken into consideration the fact that the stream must be sent with more force through the carotid and subclavian trunks, which are the continuations of the main vessel, than into the branches of the subclavian which come off at right angles, or nearly so, to the main current. Thus, I am not surprised to find that even when the subclavian and its branches have become obliterated, the carotid being pervious, the aneurism continued to make progress, as in a case of Dr. Herbert Davies, reported in the London Hospital Reports, vol. i., where the aneurism eventually burst in to the trachea. By cutting off the two main streams, and limiting the flow of blood to the branches of the subclavian artery, it appeared probable that a cure might be effected, not by the entire obstruction of the innominate artery, but by the deposit of fibrin within it and the aneurismal sac, so as to arrest the disease. $\mathbf{M r}$. Wardrop believed that the carotid was already obliterated in the case on which he first tied the subclavian for innominate aneurism; and had it been so, the result might have been different; but, as the tumour diminished, the carotid, being relieved from pressure, began to beat again, and the aneurism to make progress. In an unpublished case which M. Paul Broca has kindly communicated to me, and in which he tied the subclavian for an innominate aneurism in August, 1862, the carotid was thought to be obliterated, but proved not to be so at the patient's death in the following February, the vessel being much displaced by the pressure of the tumour, and being reduced to about half its size. In this case, however, pulsation never returned in the vessel, which was obstructed, though not obliterated; and the case therefore resembles one of simultaneous ligature of the two main trunks. The death of the patient was caused by gangrene of the lung, and was in no way attributable to the aneurism, which was filled with fibrinous clot, leaving a cavity in the centre of the size of a small fowl's egg, communicating above with the carotid and subclavian, and below with the aorta. This last case may fairly be considered a cure as far as the aneurism is concerned (though M. Broca himself speaks of it as a "half-cure" (demiquérison), and it may be classed with Mr. Fearn's wellknown case in which he tied the common carotid in 1836 , and the subclavian artery in 1838 . Here the patient died nearly four months after the second operation, from an attack of pleurisy unconnected with the aneurism, and due to an accident; and, as may be seen in the preparation in the museum of the College of Surgeons, the aneurismwhich is a sacculated one, involving the aorta in some degree, as well as the root of the innominate artery-is thoroughly filled with laminated fibrine, a canal being left for the passage of the blood into the unobliterated branches of the subclavian artery.

$\mathrm{M}_{5}$ patient made a perfect recovery from the operation. Pulsation returned in the right temporal artery on the night of the operation, and in the brachial two days after. There were never any head symptoms. The tumour did not alter in size immediately, but two days after the operation the patient was able to lie down with perfect comfort; and by the third day the tumour had decidedly altered, the pulsation could not be so distinctly felt, and there was a distinct double beat, but no bruit. By the sixth day after the operation the tumour had so much diminished that the outline of the inner end of the clavicle and upper margin of the sternum could be clearly defined, the pulsation being felt both above and below the bone. By the ninth day pulsation in the upper part of the tumour had nearly disappeared. On the eighteenth day both the ligatures came away without any hæmorrhage. Attempts were made to favour the deposit of fibrine in the aneurism by the administration of the acetate of lead, by the application of ice to the tumour, and by careful regulation of the diet, but witbout any material adrantage. 'The patient was discharged from hospital on March 6th, 1866, three months and a half after the operation, in good health, with no ssmptoms referable to the aneurism, which was now 
apparent only by a pulsation throngh a hole in the upper part of the right side of the sternum, and not in the sternoclavicular joint as had been at first supposed. The right radial pulse was feebly perceptible, and the circulation on the right side of the neck fully restored.

The next thing I heard of Julia W- was that she had been admitted into St. Bartholomew's on Sunday, April 8th, dead drunk. I visited ber on the $11 \mathrm{th}$, and found that the tumour had diminished slightly since she left the Westminster Hospital; certainly it had not increased. The pulsation appeared the same as before.

I heard nothing further until I learnt from $\mathrm{Mr}$. Hill, of the Royal Free Hospital, that Julia W- had been brought there by the police, intoxicated, on May 10th. I visited her and found a murmur at the apex of the heart, which was not present before, and rancied the tumour to be slightly more prominent. Mr. Hill informed me that Julia W- had been a nurse in the hospital four years and a half before, when she suffered from an attack of rheumatic fever with heart affection, and that when she left the hospital a lond mitral murmur could be traced from the apex of the heart to the axillary region. She was in the Royal Free Hospital until August 8th, under Dr. Cockle, to whom I am indebted for the following notes of her condition:-

"The chief feature of interest in the progress of the case while in hospital was the variation in the size of the tumour; it sometimes being quite flat, with scarcely any perceptible impulse, at other times becoming round and prominent, with strong impulse which could be both seen and felt. Sometimes the impulse gave a liquid, at other's a solid impression. When the tumour made any sudden alteration in size it was invariably preceded by a burning throbbing pain, increase of temperature, inability to lie on the back, and a sense of suffocation, with more or less vomiting, laryngeal voice, and pain in the shoulder, face, and side of the head of the right side. These remarks refer particularly to the periods of increase only of the tumour, the decrease being unattended with any symptoms of distress. She had rheumatic pains in the limbs from time to time, which were relieved by iodide of potassium. The cardiac murmur never entirely disappeared. The right ulnar pulse was for the first time discovered on July 5th. She left the Royal Free Hospital on August 8th, when the tumour was small and flat, and the impulse very slight. The treatment adopted consisted in absolute rest, the arm being kept in a sling. Opiates were given, and sedative local applications used to relieve pain."

Julia W- was next heard of at St. George's Hospital, where she was taken by the park-keepers, who had found her insensible in the park. She was suffering from great difficulty of breathing when admitted, but soon recovered, and only stayed in the hospital two days.

I then quite lost sight of my patient until the 8th of November, when, being informed that she was in the custody of the police for being intoxicated, I procured ber admission into the Westminster Hospital, and had the satisfaction of bringing her before the fellows of the Royal Medical and Chirurgical Society on the 11th of December, 1866. On her re-admission to the hospital, a year after the operation, I found that the tumour had decidedly diminished both in size and in distinctness of pulsation, though the hole in the sternum could still be felt, and it was here that the most prominent pulsation existed. The clavicle was not so much displaced as before. The woman appeared in very good health; her appetite was good, she could walk about without distress, and could lie down with perfect comfort. She said that she had occasional attacks of dyspnoa, and that these came on when she had been drinking; and this accounts for her visits to other hospitals. There was no bruit to be heard in the tumour, nor any abnormal sound in the heart.

J. W- continued to lead a very irregular life, and was taken by the police to almost every hospital in London; but the disease underwent no material alteration until about two years after she was under my care, when the resident officer of one of the institutions to which she was taken when overcome by drink unfortunately administered powerful emetics to her, not being aware of her condition. After this the tumour, which could before be felt beating through the sternum, became much more prominent, and gradually increased in size until the skin became involved and dis- coloured. I procured her admission into the St. Elizabeth's Hospital some months before her death, and she received there every kindness and attention from the authorities and from Mr. Tegart, the visiting surgeon. She then complained of constant pain in the aneurism, which was relieved by the local application of morphia, and had occasional attacks of dyspnœa and prostration. A month before her death, there having been for some time a large ecchymosis over the tumour, an arterial bleeding occurred, but this was checked by styptics. Bleedings occurred from time to time, and at last, on December 8th, 1869, she died, after a copious hæmorrhage.

On post-mortem examination the innominate artery was found to be healthy, except that it was somewhat enlarged at its origin. The arch of the aorta was extensively aneurismal. Immediately above the pulmonary artery the aorta was dilated, and presented a double pouch to the right side. Immediately above this, and extending up to, but not involving, the origin of the innominata, was the origin of the sac of the aneurism which had burst through the sternum and externally, in front of the manubrium, was the thinwalled sac full of soft coagulum, which had given way toward the left side above. On opening the aneurismal tumour within the thorax, it was found to be a distinctly sacculated aneurism, springing from the right side of the ascending portion of the arch of the aorta, higher than appeared externally, owing to the lower part of the aneurism having grown downwards, and to the right. This portion of the sac contained firm, laminated fibrine, to the thickness of one-third of an inch. The portion of the aneurism attached to the sternum contained no fibrine, except the loose clot in the outer sac. The subclavian artery was reduced to a fibrous cord, one inch in length, immediately outside the scalenus, and the right common carotid was obliterated in the whole of its course, the point of ligature being marked by a delicate fibrous cord, and the upper inch and lower two inches of the vessel forming a flat fibrous band, nearly one-fourth of an inch wide. The collateral circulation in the arm and neck had been fully established. The preparation was brought before the Pathological Society of London on April 19th, and a more detailed description, with a drawing, will appear in the next volume of the Society's Transactions.

The preceding case appears to raise a very important question in practical medicine and surgery-whether, in cases of aneurism of the arch of the aorta, it is not possible to afford relief by surgical interference. There can be no question that my patient's urgent symptoms of dyspncea and dysphagia were relieved by the double ligature, and that her life was prolonged very considerably under the most untoward circumstances. Dr. Cockle has already (The LANCET, April 10th, 1869) urged ligature of the carotid in cases of aortic aneurism which are making progress in spite of medical treatment; and when the disease involves the transverse portion of the arch, I should be inclined to follow the suggestion as regards the left carotid But when the disease involves the ascending portion of the arch, I believe the only hope of success will be in tying both the right carotid and subclavian, so as to diminish as far as possible the current through the innominata, agreeing as I do with Dr. Sibson in the importance of attacking the vessel next to the aneurism.

In reference to the cases of distal ligature, quoted by Dr. Cockle in his valuable paper already referred to, I may re mark that both the cases of Tillanus and Rigen, in which cure of an aortic aneurism followed ligature of the carotid, were examples of ligature of the left carotid, the aneurism being on the transverse portion of the arch. In Mont gomery's case the ligature was also on the left side, and the aneurism was found four months after the operation to involve the aorta between the innominate and left carotid arteries, thus supporting the view I have put forward above. In Mr. Maunder's case, in which he in 1867 followed my example of tying the two arteries on the right side for supposed innominate aneurism, the disease proved to be principally aortic, and the coagulation had extended down to the beart, and thus occasioned death. In my own case, the aneurism being more distinctly sacculated, this untoward result did not occur, nor is it to be necessarily anticipated in another case.

Before quitting the subject it may be well to note that in two cases, at least, distal pressure has given relief in 
aneurisms of the root of the neck probably involving the aorta. In the Edinburgh Journal for October, 1847, p. 229, there is a report of a case, by Dr. Lyon, in which the patient had a large aneurism of the size of the fist, reaching upwards from the sternum, on the right side. Pressure on the carotid was made at intervals, and the tumour became more solid. The patient was of intemperate habits, and died of bursting of the sac into the pleura after twenty months. The aneurism was found to involve the innominate and aorta. There was a large fibrinous deposit opposite the attachment to the right sterno-clavicular joint, and the other parts of the sac were filled with soft coagulum. In The Lancet of Jan. 9th, 1858, the late Mr. A. Mi. Edwards, of Ediuburgh, has recorded a case of supposed innominate aneurism in a woman of fifty, in whom Dr. Laycock pronounced the aorta also to be implicated, and in whom great relief of all distressing symptoms was procured by the adaptation of pressure to the right common carotid and subclavian arteries. Unfortunately the termination of the case and post-mortem appearances have not, so far as I know, been published.

Cavendish-place, June, $18 \%$.

\section{a sithror}

\section{OF THE PRACTICE OF}

\section{MEDICINE AND SURGERY IN THE}

\section{HOSPITALS OF LONDON.}

Nulla antem est alia pro certo noscendi via, nisi quamplurimas et morborum et dissectionum historias, tum aliorum, tum proprias collectas habere, et snter se comparare.-MorgagNI De Sed. et Caus. Morb., lib.iv. Proœmium.

\section{KING'S COLLEGE HOSPITAL.}

CASES OF SUCCESSFUL TREATMENT OF UTERINE CATARRH BY INTERNAL APPLICATION OF CARBOLIC ACID.

(Clinical Remarks by Dr. W. Plarfair.)

IN a large proportion of old-standing cases of uterine catarrh it is hopeless to expect a permanent cure by any means which do not act directly on the seat of the disease, which is the lining membrane of the cavity of the uterus and cervical canal beyond the external os; accompanied, of course, with secondary morbid states of the body of the uterus and cervix, such as hypertrophy, congestion, \&c. Rest, applications to the exterior of the cervix, and general treatment will unquestionably cause a temporary improvement, but on a recurrence to the old habits of life all the old symptoms return. There are serious objections to intrauterine injections, unless the os is first dilated with laminaria tents, as they are apt to bring on severe uterine colics. By means of fine probes of whalebone or flexible metal, round which a thin film of fine cotton-wool is wrapped, alterative applications can readily be made to the interior of the uterus, without pain or danger. In the very numerous cases in which this plan of treatment has been carried out, in no single instance has anything but the greatest benefit accrued. It is no doubt advisable to select the cases judiciously, and where there is much uterine tenderness, intra-uterine treatment should be postponed until this has been diminished by rest, leeching, \&c.; but with proper precautions the treatment is perfectly safe. A concentrated solution of carbolic acid, eighty parts to twenty of water, is used; and it acts so well that for a long time nothing else has been employed. After the first application the discharge is sometimes increased, but after the second or third it is generally greatly diminished, and a single application is often sufficient to cure superficial erosions of the cervix. As a rule, there is no difficulty in passing the probes, as in true uterine catarrb the os is invariably patulous. As the case improves the patulous state of the os diminishes, and this is found to be one of the most certain signs of improvement.

The following cases are selected, not because they pre- sent any peculiar features, but because each of them had been assiduously treated for lengthened periods by the ordinary methods emplojed, and without permanent relief, while they were rapidly cured as soon as the true seat of disease was attacked.

Mrs. P-, aged thirty-three, was the mother of four children, the joungest of whom was six jears of age. Ever since the birth of her last child she had suffered from uterine diseases, the prominent symptoms being constant bearingdown pain which entirely incapacitated her for work, and a very profuse leucorrhoal discharge of a transparent gelatinous character. The latter was steadily increasing, and she became now thin and cachectic. The menstrual flow was irregular, scanty, and very painful. The uterus was large, and tender on pressure; the cervix greatly hypertrophied, and covered with a villous erosion, which bled on being touched. The leucorrhoeal discharge was seen to issue freely from the os 'uteri. During six months the patient had attended the out-patient department of a metropolitan hospital, and during two months she had been treated generally, with occasional applications of tincture of iodine to the cervix. Her general health improved somewhat, but the uterine symptoms did not become much better, while the discharge continued unabated. She was then treated by the intra-uterine application of carbolic acid once a week, along with the application of iodised cotton and glycerine to the cervix. After the third application the discharge was much diminished, and the erosion of the cervix almost healed. In four months the patient was perfectly well; the uterus being of normal size, and the uterine leucorrhoa having entirely disappeared. She has since remained perfectly well in every respect.

M- aged twenty-six, domestic servant, had suffered from uterine disease for four years, with constant pain, and the discharge was so profuse that it ran freely from her, and incapacitated her for work. She had, on two occasions, been an in-door patient in a metropolitan hospital for several months, gaining only temporary relief. On examination the uterus was seen to be large and heavy, the cervix greatly eroded, and the os patulous, admitting the sound with ease. A glairy discharge was pouring out abundantly. After the fifth intra-uterine application of carbolic acid, the discharge, which had continued unabated for four years, almost entirely ceased. There remained neither pain nor bearing down. The patient was able to wall a good distance, and carry weights without inconvenience, for the first time since the onset of her illness. She had gained in flesh and general health.

Mrs. $K$ - , aged twenty-six, the mother of four children, had suffered greatly for three years from uterine disease, and had undergone a variety of treatment, including repeated leeching of uterus, and the application of potassa fusa to the cervix, without any permanent relief. She was entirely unable to walk, in consequence of bearing-down pain and profuse leucorrhoeal discharge. The menstrual flow was irregular and scanty. On examination, the uterus and cervix were both greatly hypertrophied. The latter was softened, and covered with granular erosion, which bled on being touched. Much glairy discharge exuded from the os. The uterus was anteverted, and the cervix exposed with difficulty. A band of adhesion was felt in the direction of the right broad ligament-probably the remains of an old attack of parametritis. There was, however, no swelling or tenderness on pressure in that situation.

The carbolic-acid treatment was then commenced, and from the very patulous condition of the os the probes could be passed with great ease. An immediate improvement commenced. In two months the uterus and cervix were much diminished in size, the discharge lessened, and the patient was able to walk about with ease, and to attend to her duties. In six months she was perfectly well, and the probes could no longer be passed through the os, which had resumed its natural dimensions.

\section{GUY'S HOSPITAL.}

\section{NEPHROTOMY.}

(Clinical Remarks by Mr. Bryant.)

Mr. Bryant said the case had been for some months under the care of Dr. Moxon, who had, with him, come to the conclusion that an operation should be performed. The 